\title{
Common origin of left anterior descending artery and right coronary artery from right aortic sinus: presentation of rare variant
}

\author{
J. Romanek¹, G. Staśkiewicz² ${ }^{2}$ R. Maciejewski², M. Wojtaszek³ ${ }^{3}$ M. Chlebuś1 ${ }^{1}$ \\ W. Stanik ${ }^{1}$, R. Sztembis ${ }^{1}$ \\ ${ }^{1}$ Cardiology Ward with Acute Coronary Syndromes Unit, District Hospital No. 2, Rzeszow, Poland \\ ${ }^{2}$ Human Anatomy Department, Medical University of Lublin, Poland \\ 3 Institute of Obstetric and Emergency Medicine, Rzeszow University, Rzeszow, Poland
}

[Received 25 July 2013; Accepted 20 September 2013]

\begin{abstract}
The authors discuss a case of 55-year-old man admitted to hospital with clinical symptoms and electrocardiac signs of myocardial infarction, who underwent invasive diagnosis and one of most rare coronary arteries anomaly was observed: common origin of right coronary artery and anterior interventricular artery (left anterior descending artery) from right aortic sinus. Anatomical variants of coronary arteries are rare amongst general population, ranging between $0.29 \%$ to $1.3 \%$ and such anomaly is found in $0.03 \%$ of all coronarographies and is responsible for $2.3 \%$ of all coronary variations. Knowledge about coronary arteries anomalies is helpful not only in making better diagnosis but also in making better therapeutic decisions. (Folia Morphol 2014; 73, 2: 234-237)
\end{abstract}

Key words: anomaly, coronary arteries, right aortic sinus, anterior interventricular artery

\begin{abstract}
INTRODUCTION
Heart development has been investigated both in animal and human studies [17], but molecular and cellular mechanisms of that process are not yet fully discovered and understood [19]. Heart development starts in the $3^{\text {rd }}$ week of embryonic life. Proepicardium is a key source of cells that make up the coronary vessels. The cells that make up the coronary arteries are derived from the regions around the aorta. Newest discoveries show that cells from an embryonic cardiac structure called the sinus venosus, which directs blood into the developing heart, begin to migrate and become coronary arteries. Many molecular signals influence that complicated process. The final stage is the connection of formed vessel trunks to aorta [18].
\end{abstract}

In vast majority of the population (98.7-99.71\%), heart is vasculated by 2 coronary arteries: right coronary artery (RCA) extending from the right aortic sinus and left coronary artery (LCA) with its origin in the left aortic sinus beginning with the left main, and then branching into anterior interventricular artery (LAD, left anterior descending coronary artery) and circumflex artery (Cx), and sometimes also into intermediate branch if the left main trifurcation is present $[1,3]$. Adachi classification describes several types of coronary circulation depending on variety of coronary branches, their course and range of anatomical areas supplied with blood $[11,16]$. In $85 \%$ of the population (type II according to Adachi classification), RCA is a dominant artery (vessel branches into posterior

Address for correspondence: G. Staśkiewicz, MD, PhD, Human Anatomy Department, Medical University of Lublin, ul. Jaczewskiego 4, 20-090 Lublin, Poland, tel: +48 609522 559, e-mail: grzegorz.staskiewicz@gmail.com 
descending artery - PDA and well developed posterolateral artery - PLA), while in $8 \%$ LCA is dominant one (type III in Adachi classification), what is 8 times higher in men than in women [5]; co-dominance is found in $7 \%$ of the population [9] (type I in Adachi classification). In general, LCA is much more diverse in its anatomical variations, including number of branches and their origins, both in foetal and adult life [8].

The frequency of coronary arteries anomalies, including atypical origins, aneurysms, ectasia, atresia or arteriovenous fistulas, is estimated depending on source and studies at $0.3-2.2 \%[4,10]$. Atypical origins of coronary arteries are found in $0.29-1.3 \%$ $[22,23,25]$ of population, what depends on prenatal development of cardiovascular system. $81 \%$ of all atypical variations are recognised as benign, as they do not result in serious consequences [2]. Typically they are diagnosed accidentally and remain asymptomatic. The rest of atypical variations, including Bland-White-Garland syndrome, congenital condition, where 1 or 2 coronary arteries originate from pulmonary trunk, may result in unspecified cardiac symptoms including: arrhythmias, fainting and chest pains. If not adequately treated, they may result in acute coronary syndromes, heart failure or sudden cardiac arrest $[15,21]$.

\section{CASE REPORT}

The authors present the case analysis of 55-year-old male patient with history of hypertension, admitted to hospital with clinical and electrocardiographic symptoms of ST-elevation myocardial infarction. The patient was immediately referred for cardiac catheterisation. Coronarography revealed trifurcation of the left main with residual LAD ending after first septal branch, dominant intermediate artery with net of branches typical for circumflex and with significant $90 \%$ proximal stenosis and recessive circumflex branch (Figs. 1, 2).

Right coronary artery angiogram revealed medial occlusion (what is typical for myocardial infarction), but also coronary anomaly - the artery originating together with RCA from right aortic sinus with septal branches supplying interventricular septum, what is typical for LAD.

The area supplied by artery originating together with RCA is the same as the area typically supplied by LAD - there are intervertebral branches that usually originate from LAD (Figs. 3, 4). Effective percutaneous

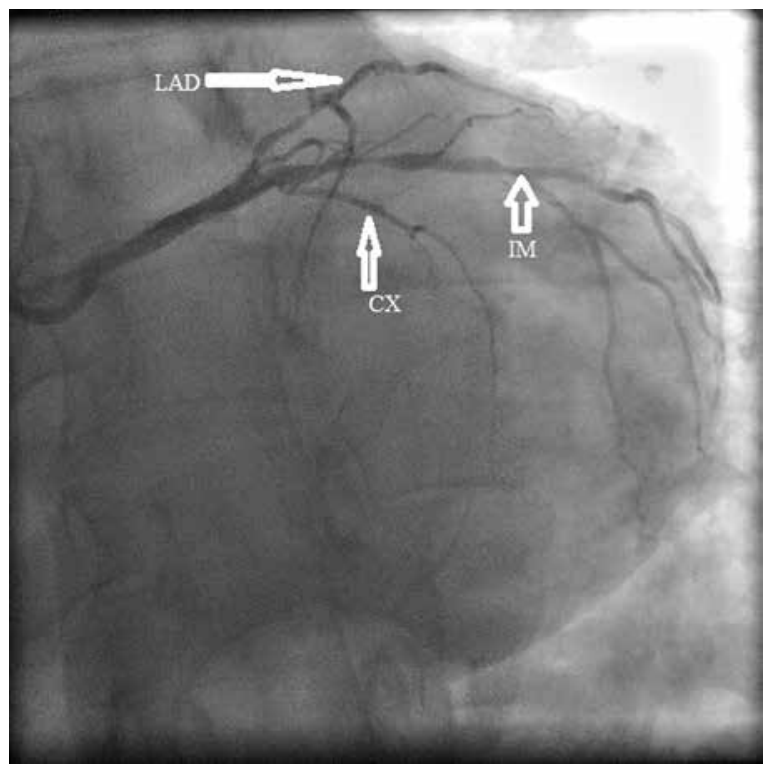

Figure 1. Coronarography, LAO 25 CAUD 25 view. Left main trifurcation - up perspective with residual left anterior descending coronary artery (LAD), then dominant intermediate artery (IM) and recessive circumflex branch (Cx).

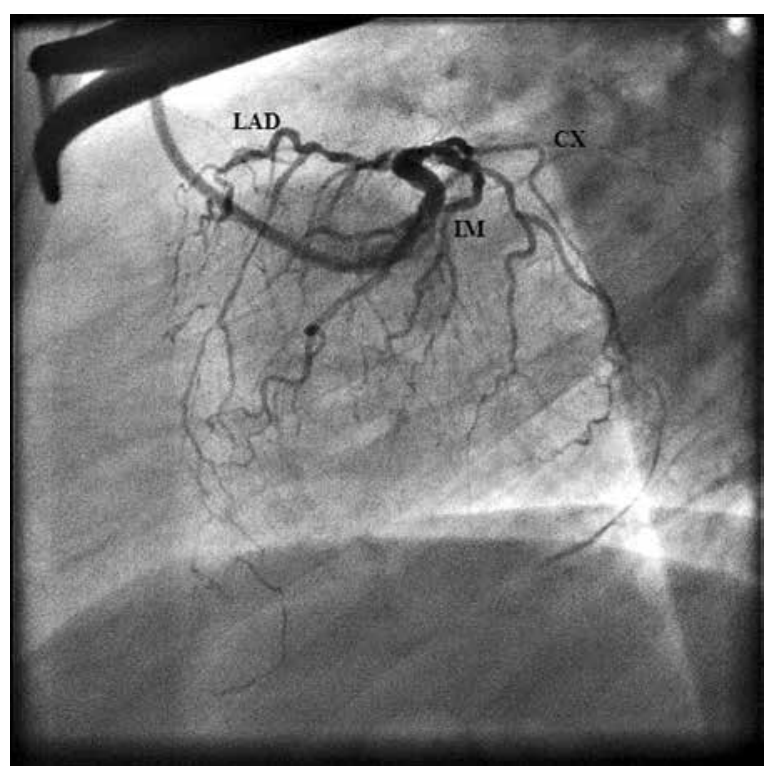

Figure 2. Coronarography, LAO 90 view. Depiction of left anterior descending coronary artery (LAD) and circumflex artery (CX); IM intermediate artery.

coronary intervention (PCI) of the RCA was performed. Further hospitalisation was uncomplicated. The patient was discharged from hospital and second stage $\mathrm{PCl}$ was planned due to significant $90 \%$ stenosis of intermediate artery.

The anomalous origin of coronary arteries in the presented patient is shown in Figure 5. 


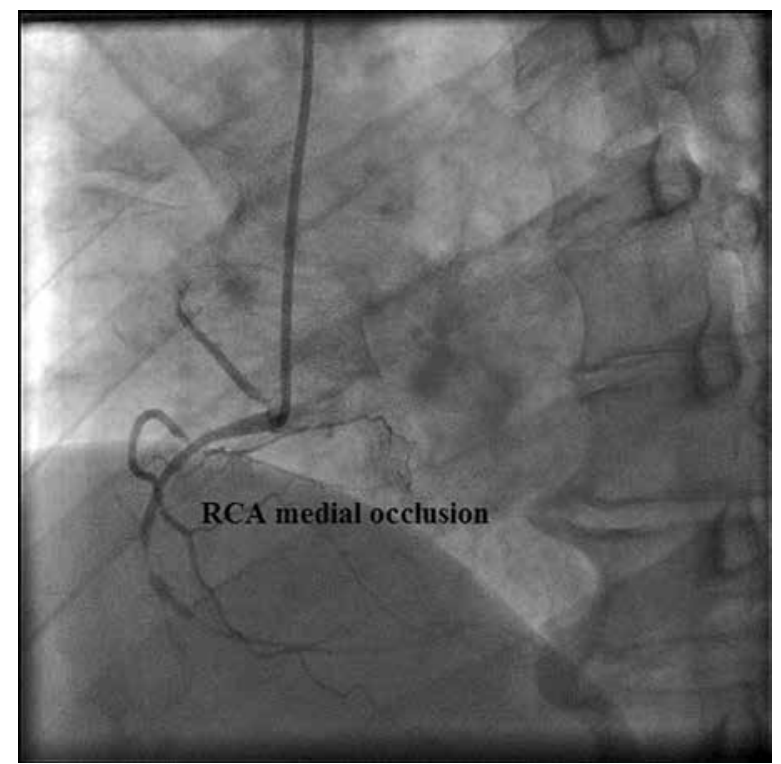

Figure 3. Coronarography, LAO 45 CRAN 5 view. Medial occlusion of right coronary artery (RCA) responsible for acute coronary syndrome and origin of artery supplying the area of left anterior descending artery.



Figure 4. Coronarography, RAO 30 CRAN 25 view. Atypical origin of artery supplying left anterior descending coronary artery (LAD) area with septal branches marked as aLAD; RCA — right coronary artery.

\section{DISCUSSION}

Presented case of common origin of RCA and LAD in right aortic sinus is recognised as potentially dangerous and is very rare. Such anomaly was diagnosed in 38 people of 126,595 who underwent coronarography between 1960 and 1988,

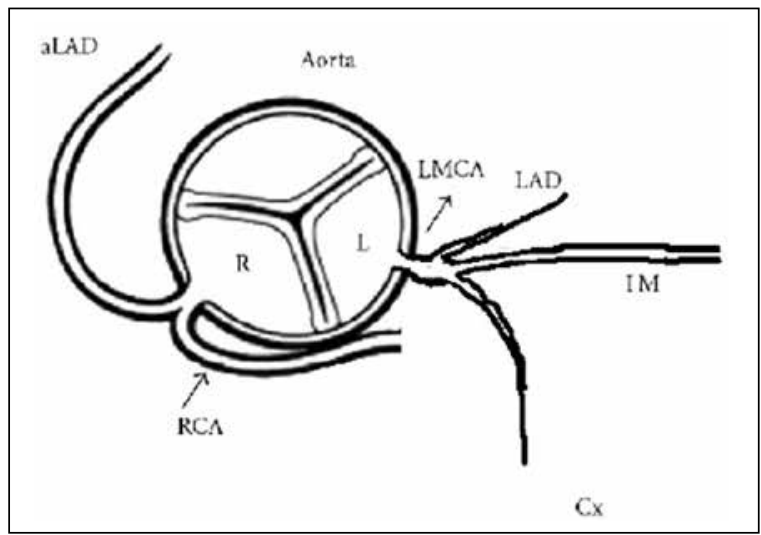

Figure 5. Schema of origin of right coronary artery (RCA) with common origin of artery supplying left anterior descending coronary artery (LAD) area with septal branches (aLAD) and left main of left coronary artery (LMCA) then branching into residual $L A D$, circumflex artery $(\mathrm{Cx})$ and intermediate artery (IM); $\mathrm{R}$ - right aortic sinus, $\mathrm{L}$ - left aortic sinus.

what is $2.3 \%$ of all the anomalies and only $0.03 \%$ of the analysed population [23]. In that case RCA was infarct-related artery and coronary anomaly was diagnosed incidentally. Nowadays cardiac catheterisation is relatively accessible tool, what means that in future more anatomical variations may be diagnosed. Nevertheless, new non-invasive assessment studies are developed like computed tomography angiography $[13,14,20]$ or magnetic resonance imaging $[7,12]$, that are potentially better diagnostic tools.

In other study of 16,573 patients between 2001 and 2011, anatomical anomaly was diagnosed in 48 cases. The origin of LAD from right aortic sinus was diagnosed in 5 cases, and in 4 of them LAD had common origin with RCA. This is $8.3 \%$ of all diagnosed anomalies and $0.024 \%$ of the study population [25]. In autopsy studies of 18,950 cases, 54 anomalies were observed and 38 of them amongst men [1]. Analyses of coronarographies performed due to different indications (stable coronary heart disease, acute coronary syndrome or before cardiac surgery) showed that anomalies are more often in men (68-74\%), and mainly these are Caucasian men.

However, it is still difficult to diagnose those atypical variations, as in most cases they are asymptomatic with normal 12-leads electrocardiogram [6]. The rest of them is responsible for highly unspecific symptoms, so they should be considered as differential diagnosis of young people presenting with unspecific cardiac symptoms. Therefore knowledge 
about coronary arteries anomalies, awareness of their potential presence and related symptoms may shorten the process of diagnosis, improve proper treatment planning and lower the risk of possible complications or mistakes during invasive procedures [24]. In the case discussed in this paper, acute coronary syndrome followed by invasive diagnosis and intervention allowed to find such rare anatomical anomaly of coronary arteries.

\section{REFERENCES}

1. Alexander RW, Griffith GC (1956) Anomalies of the coronary arteries and their clinical significance. Circulation, 14: 800-805.

2. Angelini P, Velasco JA, Flamm S (2002) Coronary anomalies: incidence, pathophysiology, and clinical relevance. Circulation, 105: 2449-2454.

3. Ballestreros LE, Ramirez LM (2008) Morphological expression of the left coronary artery: a direct anatomical study. Folia Morphol, 67: 135-142.

4. Barriales-Villa R, Morís C, López-Muniz A (2001) Anomalías congénitas de las arterias coronarias descritas en 31 aĖos de estudios coronariográficos en el Principado de Asturias: características angiográficas y clínicas. Rev Esp Cardiol, 54: 269-281.

5. Bergman RA, Afifi AK, Miyauchi R (2013) www.anastomoses.org; Anatomy Atlases: Illustrated Encyclopedia of Human Anatomic Variation: Opus II: Cardiovascular System: Arteries: Head, Neck and Thorax: Coronary Arteries: 1-5 (accessed 25.07.2013).

6. Davis JA, Cecchin F, Jones TK, Portman MA (2001) Major coronary artery anomalies in a pediatric population: Incidence and clinical importance, J Am Coll Cardiol, 37: 593-597.

7. Dewey M, Teige F, Schnapauff D (2006) Noninvasive detection of coronary artery stenoses with multislice computed tomography or magnetic resonance imaging. Ann Internal Med, 145: 407-415.

8. Ensebish S, Osch B, Narantuya N, Plunkett E, Plunkett K (2007) Morphological aspects of the coronary artery in neonates. Folia Morphol, 66: 332-338.

9. Fiss DM (2007) Normal coronary anatomy and anatomic variations. Applied Radiol, 36: 14-21.

10. Frescura C, Basso C, Thiene G (1998) Anomalous origin of coronary arteries and risk of sudden death: a study based on an autopsy population of congenital heart disease. Hum Pathol, 29: 689-695.

11. Gawlikowska-Sroka A, Miklaszewska D, Czerwiński $F$ (2009) Analysis of the influence of heart size and gender on coronary circulation type. Folia Morphol, 69: 35-41.
12. Gharib AM, Ho VB, Rosing DR, Herzka DA, Stuber $M$, Arai AE, Pettigrew RI (2008) Coronary artery anomalies and variants: technical feasibility of assessment with coronary MR angiography at 3 T. Radiology, 247: 220-227.

13. Javadrashid R, Tarzamni MK, Aslanabadi N, Ghaffari M, Salehi A, Sorteji K (2009) Myocardial bridging and coronary artery anomalies detected by ECG-gated 64-row multidetector computed tomography angiography in symptomatic patients. Folia Morphol, 68: 201-206.

14. Litt HI, Gatsonis C, Snyder B (2012) CT angiography for safe discharge of patients with possible acute coronary syndromes. N Engl J Med, 366: 1393-403.

15. Maron BJ, Thompson PD, Puffer JC (1996) Cardiovascular preparticipation screening of competitive athletes: a statement for health professionals from the Sudden Death Committee (clinical cardiology) and Congenital Cardiac Defects Committee (cardiovascular disease in the young). Circulation, 94: 850-856.

16. Nowak D, Kozłowska H, Żurada A (2011) The relationship between the dimensions of the right coronary artery and the type of coronary vasculature in human fetuses. Folia Morphol, 70: 13-17.

17. Ratajska A, Fiejka E, Siemieńska J (2000) Prenatal development of coronary arteries in the rat: morphometric patterns. Folia Morphol, 59: 297-306.

18. Red-Horse K, Ueno H, Weissman IL, Krasnow MA (2010) Coronary arteries form by developmental reprogramming of venous cells. Nature, 464: 549.

19. Reese DE, Mikawa T, Bader DM (2002) Development of the coronary vessel system. Circ Res, 91: 761-768.

20. Ropers D, Moshage W, David WG (2001) Visualization of coronary artery anomalies and their anatomic course by contrast-enhanced electron beam tomography and three-dimensional reconstruction, Am J Cardiol, 87: 193-197.

21. Wańczura P, Orłowski M, Stecko W, Węglarz M, Skoczyński K, Romanek J, Kukla P, Kuźniar J (2011) Mitral regurgitation in course of Bland-White-Garland syndrome in female patient after four uncomplicated physiological labours. Pol Merk Lek, 182: 103-105.

22. Welker M, Salanitri J, Deshpande VS, Shea SM, Li D, Pereles FS (2006) Coronary artery anomalies diagnosed by magnetic resonance angiography. Austr Radiol, 50: 114-121.

23. Yamanaka O, Hobbs RE (1990) Coronary artery anomalies in 126,595 patients undergoing coronary arteriography. Catheter Cardio Int, 21: 28-40.

24. Young-Hyman PJ, Tommaso CL, Singleton RT (1984) A new double coronary artery anomaly: the right coronary artery originating above the coronary sinus giving off the circumflex artery. J Am Coll Cardiol, 4: 1329-1331.

25. Yuksel S, Meric M, Soylu K, Gulel O, Zengin H, Demircan S, Yilmaz O, Sahin M (2011) The coronary angiographic analysis of 16573 patients for coronary artery origination and course anomalies. Eur Heart J, 32: 739. 